\title{
TRIM21 chimeric protein as a new molecular tool for multispecies IgG detection
}

\author{
Anelize Ramos ${ }^{1}$, Leonardo Fernandes ${ }^{1}$, Franciane Batista ${ }^{1}$, Maria Risoleta Freire Marques ${ }^{2}$, \\ Jacó Joaquim Mattos ${ }^{2}$, Maria de Lourdes Magalhaes ${ }^{1}$, and Gustavo da Silva ${ }^{1}$ \\ ${ }^{1}$ Universidade do Estado de Santa Catarina \\ ${ }^{2}$ Universidade Federal de Santa Catarina - Campus Florianópolis
}

July 11, 2021

\begin{abstract}
G-type immunoglobulins (IgGs) are extensively used in the pharmaceutical industry against various diseases, being also crucial in multiple immunoassays. The production of secondary monoclonal antibodies (Abs) for IgG detection is not cost-effective, while polyclonal antibody production still depends on laboratory animals, which raises concerns regarding animal welfare. As alternatives, bacterial proteins (A and G) have been widely exploited; however, several difficulties are encountered regarding their use for IgG detection and purification. The widespread use of IgGs in the pharmaceutical industry and the increasing number and variety of new Abs entering the market impose the need to develop new detection and purification strategies. The TRIM21 protein is a soluble intracellular IgG receptor that binds to the Fc region of many species with high affinity. We created a chimeric protein containing a mutated form of the C-terminal domain of mouse TRIM21 linked to a streptavidin moiety to detect IgGs from a wide range of species. The protein is promptly produced by heterologous expression and consists of an improved molecular tool, expanding the portfolio of Ab-affinity ligands for immunoassays.
\end{abstract}

\section{Introduction}

G-type immunoglobulins (IgGs) are widely used as therapeutic agents and molecular tools for antigen detection in immunoassays. IgG recognition primarily relies on polyclonal secondary antibodies (anti-IgGs), whose production has not changed significantly over the last decades. Therefore, the use of laboratory animals is still necessary, which raises essential concerns regarding animal welfare. The European Union (EU) directive on protecting animals used for scientific purposes urges animal-free alternatives for antibody (Ab)based technologies. Furthermore, the use of polyclonal secondary Abs presents several limitations, including batch-to-batch variability and size limitations, as well as high cross-reactivity. Also, after their production, these Abs are chemically coupled to enzymes/ fluorophores. These conjugations yield randomly cross-linked products, which require additional purification procedures resulting in diminished yields and increased costs (Farr \& Nakane, 1981). Such limitations impose the search for superior alternatives. Besides the technologies mentioned above, IgGs can be detected/purified by the use of bacterial proteins such as G (from Streptococcus spp ), A (from Staphylococcus aureus ), or L protein (from Peptostreptococcus magnus ). Chimeric proteins using the bacterial proteins mentioned above linked to signal emitting proteins produced several IgG detection probes (Sano \& Cantor, 1991; Strandberg, Hober, Uhlen, \& Enfors, 1990; Sun \& Lew, 1992; Xxxx et al., 2018). The production of A, G, or L proteins is not as costly and complex as secondary Abs. Still, it presents several disadvantages, given their limited IgG affinities against species or IgG subclasses, limiting their use. For example, Protein A binds rabbit, pig, dog, and cats IgGs, among others, but does not bind human IgG isotype 3 (IgG3) (Jendeberg et al., 1997), and also fails to bind horse, rat, or sheep IgGs (Van Loghem, Frangione, Recht, \& Franklin, 1982). 
IgG3 in human serum has been linked to exposure and protective immunity against protozoan (Soe, Theisen, Roussilhon, Aye, \& Druilhe, 2004) (Roussilhon et al., 2007). L protein binds only kappa light chains Abs (Nilson, Solomon, Bjorck, \& Akerstrom, 1992), and therefore, alpha light chain Abs are not detected using $\mathrm{L}$ protein. IgG species/subclasses that do not bind well to protein A generally bind to protein $\mathrm{G}$, making those molecules complementary binding options for immunoassays. Although protein G possesses a better binding capacity for a broader range of mouse and human IgG subclasses (Saha, Bender, \& Gizeli, 2003), it does not bind $\operatorname{IgM}$, IgA, IgE, or IgD (Mouratou, Behar, \& Pecorari, 2015). In addition, protein $\mathrm{G}$ has an albumin-binding site, a significant constituent of serum proteins, debilitating its use. Affinity chromatography employing immobilized bacterial proteins is a well-established technology for industrial-scale monoclonal antibody purification. However, such resins are costly and account for a significant proportion of IgG production costs (60-80\%) (Gronemeyer, Ditz, \& Strube, 2014). In addition, another major obstacle hampering the use of bacterial proteins is sample contamination with trace amounts of these bacterial proteins, which can induce a host immune response. Furthermore, IgG purification using Protein A/G coupled resins requires acidic buffers for proper elution, resulting in Ab denaturation and loss of function.

Accordingly, there is a need to develop affinity ligands for IgG detection and purification to decrease costs and increase efficiency. New molecular tools have been created in recent years to expand the pool of antibody binding ligands and overcome the drawbacks associated with the use of bacterial proteins,

A recent paper described camelid nanobodies to replace secondary antibodies (Pleiner, Bates, \& Gorlich, 2018). These molecules can be primarily expressed in E. coli , but present specificity against sole rabbit and mouse IgGs and need further coupling to signal emitting molecules.

The Tripartite motif-containing protein 21 (TRIM21) protein is a soluble intracellular IgG receptor that binds to the Fc region with high affinity (Keeble, Khan, Forster, \& , 2008; McEwan, 2016; Rhodes \& Trowsdale, 2007; Yang, Eversole, Lee, Sontheimer, \& Capra, 1999). This protein presents a broad antibody specificity, which includes binding to murine, dog, non-human primate, and human IgGs (Keeble et al., 2008) as well as IgM (James, 2014). As opposed to protein A, TRIM21 binds all human IgG isotypes with high affinity, including IgG 1, 2, 3, and 4 (Keeble et al., 2008). TRIM21 structure consists of an N-terminal RING domain, a B-box domain, a central coiled-coil domain, and a C-terminal PRYSPRY domain (James, Keeble, Khan, Rhodes, \& Trowsdale, 2007). Earlier studies demonstrated that the portion responsible for IgG binding corresponds to its C-terminal PRYSPRY domain (Rhodes \& Trowsdale, 2007). Crystal structure of the C-terminal PRYSPRY domain in complex with human IgG1 has been solved, allowing a deep understanding of the molecular interactions that resulted in the complex formation. The complex revealed binding of one PRYSPRY domain on each Fc side, resulting in a 2:1 stoichiometry. The full-length protein dimerizes through its coiled-coil domain. Upon IgG binding, it engages both heavy chains simultaneously, resulting, in higher affinity constants $(\mathrm{Kd}=0.5 \mathrm{nM})$, when compared to the monomeric C-terminal PRYSPRY domain (James et al., 2007).

This study assessed the potential of using the C-terminal domain of TRIM21 PRYSPRY domain as a multispecies IgG binding module to produce chimeric proteins that can detect multi-specie IgGs in immunoassays. Therefore, mouse TRIM21 PRYSPRY (S370L) mutant was used as IgG binding module, since previous alanine scanning studies (James et al., 2007) indicated that the presence of Leucine at position 370 provides higher enthalpy contributions for binding into a human as well as murine IgG (Keeble et al., 2008). We created a chimeric protein containing an N-terminal streptavidin coding sequence followed by a rigid linker composed of four repeats of EAAAK residues and mouse PRYSPRY domain (S370L). The streptavidin portion will allow the coupling of up to four biotinylated molecules per tetramer, including other biotinylated molecules such as enzymes and fluorophores. Data reported here introduces a new and improved molecular tool for IgG detection comparable to the well-established bacterial A and G proteins, expanding the possibilities for biotechnological developments in immunoassays.

\section{Results and Discussion}

\section{Protein Engineering, Expression and Purification}


The three-dimensional structure of the C-terminal PRYSPRY domain of mouse TRIM21 (Red) in complex with mouse IgG (Blue) is represented in Figure 1A, demonstrating that binding occurs between TRIM21 and the Fc domain of the immunoglobulin. Competition binding experiments reported earlier showed that TRIM21 binds to the Protein A and G binding site in the Fc domain of IgGs (James et al., 2007). A schematic diagram of the chimeric protein is shown in Figure 1B. The N-terminal end of the protein encloses a polyhistidine tag for purification purposes followed by the streptavidin core gene as described by Cantor (Sano \& Cantor, 1990), a rigid [EAAAK] 4 peptide repeat, and, lastly, the C-terminal PRYSPRY domain of mouse TRIM21 (S370L mutant). The mouse TRIM21-PRYSPRY S370L mutant was chosen since previous alanine scanning studies demonstrated high enthalpy contributions of this residue (Leucine 370) upon TRIM21 binding into human and murine IgGs (James et al., 2007). Therefore, a protein with broader IgG specificity was intended by creating a module that detects both human and mouse IgG. The chimeric SA-TRIM21 gene was designed, so the C-terminal PRYSPRY domain binds IgGs, and the streptavidin domain is freely available for biotin binding, therefore not precluding PRYSPRY domain binding into IgG (Figure 1C).

The EAAAK is a rigid alpha helix-forming linker that is applied to the construction of many recombinant fusion proteins (Chen, Zaro, \& Shen, 2013). The $\alpha$-helical structure with intra-segment hydrogen bonds and a closely packed backbone acts as a rigid spacer. Therefore this linker was chosen to minimize possible interactions between the two protein domains. The streptavidin core moiety (residues 13-139) was used because removing streptavidin $\mathrm{N}$ and $\mathrm{C}$ termini is necessary for the high-affinity biotin-binding to allow coupling of biotinylated enzymes, fluorophores, and nanoparticles.

SA-TRIM21 chimeric protein was expressed as inclusion bodies followed by denaturation using Guanidine Hydrochloride and protein refolding through dialysis. Denaturation and refolding are essential, assuring endogenous biotin is removed, and all streptavidin binding sites are unoccupied. Glucose and glycine present in dialysis buffer assisted streptavidin refolding in previous studies (Modanloo Jouybari, Sadeghi, Khansarinejad, Sadoogh Abbasian, \& Abtahi, 2018). Therefore these compounds were used to help chimeric protein refolding. Streptavidin is toxic for many E.coli strains, and alternative strains are used for streptavidin expression. Here we used E.coli BL21(DE3)pLysS to circumvent toxicity, and free biotin (2 mg/L) was added as earlier reported (Jeschek et al., 2017). A total of $10 \mathrm{mg}$ of soluble purified chimeric protein was obtained per liter of culture. Purified protein was stored at $-20^{\circ} \mathrm{C}$ and used for immunoassays as described below.

\section{IgG and animal serum detection using SA-TRIM21}

We first investigated the performance of the streptavidin domain by SA-TRIM21 immobilization into microplates followed by incubation with biotin-HRP. Figure 2A shows that the streptavidin domain is functional, capturing biotinylated HRP efficiently in a dose-dependent manner. Next, we investigated SATRIM21 ability to bind mouse serum on a direct ELISA assay. Figure 2B shows that SA-TRIM21 (0.5 $\mu \mathrm{g} /$ well) detected mouse serum (50 ng) more efficiently than commercial polyclonal anti-mouse IgG coupled to HRP. Control experiments were performed by immobilizing human lactoferrin, which produced a negligible signal, confirming the specific binding. These data demonstrate that the chimeric protein retains both domains' functionality.

We also tested the best stoichiometric ratios between SA-TRIM21 and biotinylated HRP (Figure S1). The SA-TRIM21:HRP molar ratio that produced the highest signal/noise ratio was 4:1, suggesting that additional HRP may cause sterical hindrance that causes PRYPSRY domain loss of function.

In addition, we tested SA-TRIM21 as a secondary antibody substitute on an indirect ELISA assay (Figure 3 ). For that, we coated microtiter plates with $75 \mathrm{ng}$ purified tumor necrosis factor-alpha protein (TNF- $\alpha$ ). After, we added diluted human serum containing infliximab (anti-TNF- $\alpha$ IgG1). Figure 3 shows that the chimeric protein efficiently detected infliximab bound to TNF- $\alpha$.

Experiments using serum from a wide range of animals were performed to investigate chimeric protein specificity, and data is shown in Figure 4. As can be observed, SA-TRIM21 recognizes serum antibodies from bovine, mouse, dog, rat, horse, pig, sheep, rabbit, and humans, but not cats. This data is consistent with previous studies using the C-terminal domain of mouse TRIM21, which demonstrated that interaction 
is highly conserved, displaying broad cross-species reactivity from a range of mammals (Keeble et al., 2008).

According to the affinity studies, binding affinity towards the mouse, human and canine IgGs are very similar. Therefore, the increased signal observed for canine and human sera compared to mice might be a consequence of S370L mutation or due to more significant IgG titers on these species.

The interaction between the C terminal PRYSPRY domain in complex with mouse IgG1 has been previously solved, allowing a deep understanding of the molecular interactions of the complex (James et al., 2007).

In addition, alanine scanning studies on the residues involved in binding depicted four hot spot residues on TRIM21 (D355, W381, W383, and F450) and three hot spot residues on the mouse Fc domain (H433, N434, and H435) (James, Keeble, Khan, Rhodes, \& Trowsdale, 2007). Protein alignment studies demonstrated that the HNH motif is highly conserved among all tested species, except in cats (Figure 5). Therefore, the absence of SA-TRIM21 binding in cat serum indicates that Serine at position 434 disrupts IgG binding. Since two Fc hot-spot residues are histidines, we reasoned that imidazole elution might be an option for IgG elution using TRIM21 based purification strategies. Therefore, we performed direct ELISA assays using immobilized human serum, followed by washing with imidazole-containing buffers (Figure 6). One can observe that imidazole disrupts SA-TRIM21 binding but not Protein A/G binding. Therefore, the possibility of IgG capture using SA-TRIM21 followed by imidazole elution may represent an innovative IgG purification strategy based on neutral $\mathrm{pH}$ procedures. Additional studies to assess the potential of the chimeric protein on SA-TRIM21- based resins for IgG purification are currently underway.

Previous studies demonstrated that TRIM21 binding into IgG is sensitive to high salt concentrations (Keeble et al., 2008). Therefore, we investigated the role of increasing ionic strength in chimeric protein binding. As shown in Figure S2, salt concentations above $40 \mathrm{mM}$ decrease SA-TRIM21 binding and therefore, SATRIM21 based immunoassays will require reduced ionic strength conditions for binding/detection. Thus, all assays using SA-TRIM21 as a molecular probe for IgG detection require low salt PBST buffers (10 mM $\mathrm{NaCl}$ ) for binding and washing.

SA-TRIM21 was also used for IgG detection in western blot analysis (Figure 7), demonstrating that the chimeric protein efficiently recognizes membrane-bound Abs.

Comparison with protein A and G coupled to HRP from two different vendors using serum from numerous species demonstrated that SA-TRIM21 is a multispecies detection probe with broader specificity than traditional Protein A and G detection probes (Figure S3).

Since bacterial proteins $\mathrm{A}$ and $\mathrm{G}$ have complementary binding patterns, a fusion protein enclosing both proteins generated broader reporter molecules (Eliasson et al., 1988; Sun \& Lew, 1992). More recently, engineered proteins were selected to recognize different epitopes within human IgG and exhibited binding affinities in the nanomolar range (Behar et al., 2013). However, although IgG binders of high thermal and $\mathrm{pH}$ stability were generated, they mostly recognized human IgGs of subclasses 1 and 2, therefore hampering their use as multispecies molecular tools for IgG detection.

Data reported here demonstrates that SA-TRIM21 chimeric protein is an efficient and multispecies IgG detection probe for ELISA and western blot analysis. The development of new Ab-affinity ligands (recombinantly expressed in E. coli ) is crucial to assist IgG detection and pave the way for new purification strategies. The efficient elution using imidazole is an important feature that may allow the development of IgG affinity resins, using neutral $\mathrm{pH}$ and standard imidazole-containing buffers.

\section{Materials and methods}

\section{Materials}

The ethics in human research committee of the State University of Santa Catarina has approved this study (4.406.300). The animal serum used in this study was kindly provided by the Veterinary Hospital of the State University of Santa Catarina, and Scienco Biotech kindly provided tetramethylbenzidine (ONE STEP-TMB Linear, Scienco Biotech). The following IgG detection probes were used for immunoassays: HRP-conjugated 
Protein A (\#95217)/ HRP-conjugated Protein G (\#64256837) were purchased from Bio-rad (Hercules, CA, United States). HRP-conjugated Protein A (\#101023)/HRP-conjugated Protein G (\#101223) were purchased from Thermo-Fisher (Waltham, MA USA). HRP-conjugated anti-mouse IgG (\#A4416, Sigma), HRP-conjugated anti-cattle IgG (\#A5295, Sigma), HRP-conjugated anti-dog IgG (\#A6792, Sigma), HRPconjugated anti-rat IgG (\#A9037, Sigma), HRP-conjugated anti-horse (\#A6917, Sigma), HRP-conjugated anti-pig IgG (\#A5670, Sigma) and HRP-conjugated anti-human IgG (\#A170, Sigma) were used in this study.

\section{Chimeric protein gene design}

Streptavidin-TRIM21 (SA-TRIM21) chimeric gene was designed by insertion of the wild-type core streptavidin coding sequence (residues 13-140 of the mature full-length protein) (Sano, Pandori, Chen, Smith, \& Cantor, 1995) at the N-terminal end of the construct, followed by a rigid linker (five repetitive sequences of EAAAK) and the C-terminal PRYSPRY domain (S370L) gene sequence of mouse TRIM21. SA-TRIM21 gene sequence was synthesized and cloned into pET15b(+) vector between Nde I eXho I restriction sites and purchased from Genescript $\AA$. Their schematic design of the primary structure and the putative quaternary structure is shown in Figure 1B.

\section{Protein Expression and Purification}

Recombinant plasmids were transformed into E. coli BL21 pLysS (DE3). Cells were inoculated into LuriaBertani Broth (LB) media containing appropriate antibiotics (ampicillin $100 \mu \mathrm{g} / \mathrm{mL}$ and chloramphenicol 35 $\mu \mathrm{g} / \mathrm{mL}$ ) and biotin $2 \mu \mathrm{g} / \mathrm{mL}$ and cultivated at $37 \mathrm{oC}$ until reach $600 \mathrm{~nm}$ optical density (OD) of 0.6 followed by induction with $0.1 \mathrm{mM}$ IPTG at $37^{\circ} \mathrm{C}$ for $12 \mathrm{~h}$. Cells were centrifuged, and the bacterial pellet was suspended in $50 \mathrm{mM}$ Tris, $300 \mathrm{mM} \mathrm{NaCl}$ containing $50 \mathrm{mg}$ DNASE, $100 \mathrm{mg} / \mathrm{mL}$ PMSF, and $1 \mathrm{mg} / \mathrm{mL}$ lysozyme followed by cell disruption through sonication. The bacterial cell lysate was centrifuged, and the insoluble cell fraction was washed five times with $50 \mathrm{mM}$ Tris $\mathrm{pH} 8.0,300 \mathrm{mM} \mathrm{NaCl}, 5 \mathrm{mM}$ EDTA, 0,1\% Triton X-100 and centrifuged at $10.000 \mathrm{rpm}$ for $10 \mathrm{~min}$. The insoluble pellet was then solubilized with $6 \mathrm{M}$ guanidine hydrochloride, $20 \mathrm{mM}$ phosphate $\mathrm{pH} 1.5$ for $1 \mathrm{~h}$ at $37^{\circ} \mathrm{C}$ and dialyzed against Refolding Buffer $(0.2 \mathrm{M}$ ammonium acetate, $0,02 \%$ sodium azide, $5 \%$ sucrose, PMSF and 0,1\% Tween-20) for protein refolding. The refolded protein extract was then dialyzed against $50 \mathrm{mM}$ Tris $\mathrm{pH} 8.0,300 \mathrm{mM} \mathrm{NaCl}, 0.1 \%$ Tween-20, and applied onto a Ni-NTA Resin. The resin was washed with 10 column volumes $(\mathrm{CV})$ of $50 \mathrm{mM}$ Tris-HCl $\mathrm{pH} 8.0,40 \mathrm{mM}$ imidazole to remove weakly bound proteins, and protein was eluted with $3.5 \mathrm{CV}$ of $50 \mathrm{mM}$ Tris- $\mathrm{HCl} \mathrm{pH} 8,300 \mathrm{mM}$ imidazole.

\section{Western blot analysis}

Protein extracts were fractionated by SDS-PAGE and transferred into a nitrocellulose membrane according to the manufacturer's protocols (Bio-Rad@). After incubation with $1 \%$ skimmed milk in TBST for 2 hours, the membrane was washed three times with TBST and incubated with mouse anti-His-tag antibody (Sigma Aldrich $\AA, 1: 5000)$, at room temperature for two h. For HRP labeled western blots, membranes were washed three times with TBST-Low salt $(10 \mathrm{mM} \mathrm{NaCl})$ and incubated with $2,5 \mathrm{mg} / \mathrm{mL}$ HRP conjugated SA-TRIM21 or HRP-conjugated anti-mouse IgG for two h. Blots were washed with TBST- Low salt (10 $\mathrm{mM} \mathrm{NaCl})$ three times and developed with ECL-Luminol (Scienco Biotech) according to the manufacturer's protocols.

\section{Enzyme-linked immunosorbent assay (ELISA) analysis}

All ELISA assays were performed into 96 wells high binding microtiter plates. For direct ELISA assays, wells were coated $\left(18 \mathrm{~h}, 4^{\circ} \mathrm{C}\right)$ with purified $\mathrm{IgG}$ or animal serum in $50 \mu \mathrm{l}$ coating buffer $(0.05 \mathrm{M}$ Na2CO3, $0.05 \mathrm{M}$ NaHCO3, pH 9.6) and blocked with 1\% BSA in TBST. Next, HRP coupled SA-TRIM21 was added to the wells and incubated for one $\mathrm{h}$ at room temperature. Plates were washed five times with PBST-Low salt (10 $\mathrm{mM} \mathrm{NaCl}$ ) after each step. The reaction was visualized by adding $50 \mu \mathrm{L}$ chromogenic substrate (ONE STEP TMB, Scienco Biotech) for $10 \mathrm{~min}$. The reaction was quenched with $50 \mu \mathrm{L} \mathrm{H}_{2} \mathrm{SO}_{4} 0.16 \mathrm{~N}$, and absorbance at $450 \mathrm{~nm}$ was measured using an ELISA plate reader.

Indirect Elisa assays were performed immobilizing TNF alpha on high binding microtiter plates in $50 \mu \mathrm{L}$ coating buffer $\left(0.05 \mathrm{M} \mathrm{Na}_{2} \mathrm{CO}_{3}, 0.05 \mathrm{M} \mathrm{NaHCO}_{3}, \mathrm{pH} 9.6\right)$ and blocked with $1 \%$ BSA. Next, infliximab 
$3 \mu \mathrm{g} / \mathrm{mL}$ was added to the wells for $1 \mathrm{~h}$ at room temperature. Plates were washed five times with TBST and added SA-TRIM-HRP $(2,5 \mu \mathrm{g} / \mathrm{mL}$ ) or anti-human HRP IgG (Sigma Aldrich@) to the wells (1h, room temperature). The reaction was visualized by the addition of $50 \mu \mathrm{L}$ chromogenic substrate (TMB) for 30 min. The reaction was stopped with $50 \mu \mathrm{L} \mathrm{H}_{2} \mathrm{SO}_{4}$ and absorbance at $450 \mathrm{~nm}$ was measured using an ELISA plate reader.

\section{Conclusion}

Secondary antibody production methods have recently relied on recurrent animal immunization and serum harvesting and purification. These batches, enriched with anti-IgG polyclonal antibodies, continue to be used as high-quality reagents for research and diagnostics. However, the inherent technical limitations and ethical concerns raised by polyclonal antibodies have prompted scientists to develop animal-free techniques for secondary antibody production. More importantly, mAbs for diagnostic and therapeutic use has increased extensively, currently imposing the need for an improved portfolio of affinity ligands for IgG detection and purification. Data reported here provides an additional and superior alternative to the use of polyclonal secondary.

\section{Acknowledgments}

The authors would like to thank the Veterinary Hospital (HCV) from the State University of Santa Catarina for providing the animal serum tested in this study.

\section{Conflict of interest}

SA-TRIM21 is patented by the State University of Santa Catarina (BR 102017018782 9). Scienco Biotech is licensed to commercialize SA-TRIM21. Maria de Lourdes Magalhaes and Gustavo Felippe da Silva are co-founders of Scienco Biotech.

\section{Funding}

The authors received financial support from State University of Santa Catarina (UDESC), Fundação de Amparo à Pesquisa do Estado de Santa Catarina (FAPESC) and SENAI.

\section{References}

Behar, G., Bellinzoni, M., Maillasson, M., Paillard-Laurance, L., Alzari, P. M., He, X., . Pecorari, F. (2013). Tolerance of the archaeal Sac7d scaffold protein to alternative library designs: characterization of antiimmunoglobulin G Affitins. Protein Eng Des Sel, 26(4), 267-275. doi:10.1093/protein/gzs106

Chen, X., Zaro, J. L., \& Shen, W. C. (2013). Fusion protein linkers: property, design and functionality. Adv Drug Deliv Rev, 65(10), 1357-1369. doi:10.1016/j.addr.2012.09.039

Eliasson, M., Olsson, A., Palmcrantz, E., Wiberg, K., Inganas, M., Guss, B., . . Uhlen, M. (1988). Chimeric IgG-binding receptors engineered from staphylococcal protein A and streptococcal protein G. J Biol Chem, 263(9), 4323-4327.

Farr, A. G., \& Nakane, P. K. (1981). Immunohistochemistry with enzyme-labeled antibodies: a brief review. J Immunol Methods, 47(2), 129-144.

Gronemeyer, P., Ditz, R., \& Strube, J. (2014). Trends in Upstream and Downstream Process Development for Antibody Manufacturing. Bioengineering (Basel), 1(4), 188-212. doi:10.3390/bioengineering1040188

James, L. C. (2014). Intracellular antibody immunity and the cytosolic Fc receptor TRIM21. Curr Top Microbiol Immunol, 382, 51-66. doi:10.1007/978-3-319-07911-0_3

James, L. C., Keeble, A. H., Khan, Z., Rhodes, D. A., \& Trowsdale, J. (2007). Structural basis for PRYSPRY-mediated tripartite motif (TRIM) protein function. Proc Natl Acad Sci U S A, 104(15), 62006205. doi:10.1073/pnas.0609174104 
Jendeberg, L., Nilsson, P., Larsson, A., Denker, P., Uhlen, M., Nilsson, B., \& Nygren, P. A. (1997). Engineering of $\mathrm{Fc}(1)$ and $\mathrm{Fc}(3)$ from human immunoglobulin $\mathrm{G}$ to analyse subclass specificity for staphylococcal protein A. J Immunol Methods, 201(1), 25-34. doi:10.1016/s0022-1759(96)00215-3

Jeschek, M., Bahls, M. O., Schneider, V., Marliere, P., Ward, T. R., \& Panke, S. (2017). Biotinindependent strains of Escherichia coli for enhanced streptavidin production. Metab Eng, 40, 33-40. doi:10.1016/j.ymben.2016.12.013

Keeble, A. H., Khan, Z., Forster, A., \& James, L. C. (2008). TRIM21 is an IgG receptor that is structurally, thermodynamically, and kinetically conserved. Proc Natl Acad Sci U S A, 105(16), 6045-6050. doi:10.1073/pnas.0800159105

McEwan, W. A. (2016). Surveillance for Intracellular Antibody by Cytosolic Fc Receptor TRIM21. Antibodies (Basel), 5(4). doi:10.3390/antib5040021

Modanloo Jouybari, R., Sadeghi, A., Khansarinejad, B., Sadoogh Abbasian, S., \& Abtahi, H. (2018). Production of Recombinant Streptavidin and Optimization of Refolding Conditions for Recovery of Biological Activity. Rep Biochem Mol Biol, 6(2), 178-185.

Mouratou, B., Behar, G., \& Pecorari, F. (2015). Artificial affinity proteins as ligands of immunoglobulins. Biomolecules, 5(1), 60-75. doi:10.3390/biom5010060

Nilson, B. H., Solomon, A., Bjorck, L., \& Akerstrom, B. (1992). Protein L from Peptostreptococcus Magnus binds to the kappa light chain variable domain. J Biol Chem, 267(4), 2234-2239.

Pleiner, T., Bates, M., \& Gorlich, D. (2018). A toolbox of anti-mouse and anti-rabbit IgG secondary nanobodies. J Cell Biol, 217(3), 1143-1154. doi:10.1083/jcb.201709115

Rhodes, D. A., \& Trowsdale, J. (2007). TRIM21 is a trimeric protein that binds IgG Fc via the B30.2 domain. Mol Immunol, 44(9), 2406-2414. doi:10.1016/j.molimm.2006.10.013

Roussilhon, C., Oeuvray, C., Muller-Graf, C., Tall, A., Rogier, C., Trape, J. F., . . Druilhe, P. (2007). Longterm clinical protection from falciparum malaria is strongly associated with IgG3 antibodies to merozoite surface protein 3. PLoS Med, 4(11), e320. doi:10.1371/journal.pmed.0040320

Saha, K., Bender, F., \& Gizeli, E. (2003). Comparative study of IgG binding to proteins G and A: nonequilibrium kinetic and binding constant determination with the acoustic waveguide device. Anal Chem, 75(4), 835-842. doi:10.1021/ac0204911

Sano, T., \& Cantor, C. R. (1990). Expression of a cloned streptavidin gene in Escherichia coli. Proc Natl Acad Sci U S A, 87(1), 142-146. doi:10.1073/pnas.87.1.142

Sano, T., \& Cantor, C. R. (1991). A streptavidin-protein A chimera that allows one-step production of a variety of specific antibody conjugates. Biotechnology (N Y), 9(12), 1378-1381. doi:10.1038/nbt1291-1378

Sano, T., Pandori, M. W., Chen, X., Smith, C. L., \& Cantor, C. R. (1995). Recombinant core streptavidin. A minimum-sized core streptavidin has enhanced structural stability and higher accessibility to biotinylated macromolecules. J Biol Chem, 270(47), 28204-28209. doi:10.1074/jbc.270.47.28204

Soe, S., Theisen, M., Roussilhon, C., Aye, K. S., \& Druilhe, P. (2004). Association between protection against clinical malaria and antibodies to merozoite surface antigens in an area of hyperendemicity in Myanmar: complementarity between responses to merozoite surface protein 3 and the 220-kilodalton glutamate-rich protein. Infect Immun, 72(1), 247-252. doi:10.1128/iai.72.1.247-252.2004

Strandberg, L., Hober, S., Uhlen, M., \& Enfors, S. O. (1990). Expression and characterization of a tripartite fusion protein consisting of chimeric IgG-binding receptors and beta-galactosidase. J Biotechnol, 13(1), 83-96.

Sun, S., \& Lew, A. M. (1992). Chimaeric protein A/protein G and protein G/alkaline phosphatase as reporter molecules. J Immunol Methods, 152(1), 43-48. 
Van Loghem, E., Frangione, B., Recht, B., \& Franklin, E. C. (1982). Staphylococcal protein A and human IgG subclasses and allotypes. Scand J Immunol, 15(3), 275-278.

Xxxx, P., Minamihata, K., Tatsuke, T., Lee, J. M., Kusakabe, T., \& Kamiya, N. (2018). Expression and Activation of Horseradish Peroxidase-Protein A/G Fusion Protein in Silkworm Larvae for Diagnostic Purposes. Biotechnol J, 13(6), e1700624. doi:10.1002/biot.201700624

Yang, Y., Eversole, T., Lee, D. J., Sontheimer, R. D., \& Capra, J. D. (1999). Protein-protein interactions between native Ro52 and immunoglobulin G heavy chain. Scand J Immunol, 49(6), 620-628.

\section{Figure Legends}

Figure 1: Schematic diagram showing chimeric protein.Panel A : A 3D- structure of Mouse IgG (blue) bound to the PRYSPRY domain of wild-type mouse TRIM21 (red). Panel B: The primary and quaternary structure of SA-TRIM21. In red is represented the PRYSPRY domain of TRIM21. In purple is represented the rigid EAAAK linker, in orange is shown the streptavidin domain and in yellow the Polihistidine tag. Panel C: The graphical summary of SA-TRIM21 recognizing the antigen/antibody complex and performing signaling by biotin-HRP capture.

Figure 2: SA-TRIM21 functional assays. Panel A: The performance of streptavidin domain: SA-TRIM21 (0-500 ng) was coated into polystyrene plates followed by detection using Biotin-HRP (1:2500). Panel B: Detection of immobilized mouse serum. Mouse serum (50 ng) was coated onto polystyrene plates and detected using HRP-coupled anti-mouse IgG (Sigma, 1:10.000) or 500 ng SATRIM21 followed by incubation with biotinylated HRP (dil:1:2500). Control experiments were performed using mouse IgG and biotinylated HRP in the absence of SA-TRIM21. Experiments were performed in triplicates, and error bars represent standard deviation. In Panels A and B, wells were washed, $50 \mu \mathrm{L}$ chromogenic substrate TMB was added to the wells, incubated for 10 minutes, followed by the addition of $50 \mu \mathrm{L} \mathrm{H}_{2} \mathrm{SO}_{4}$ to quench the reaction followed by $\mathrm{OD}_{450} \mathrm{~nm}$ reading using an ELISA plate reader.

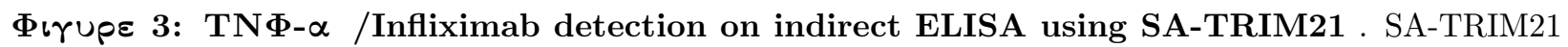
$(0.25 \mu \mathrm{g} /$ well $)$ and biotinylated HRP (1:5000) were added to the plates for TNF $\alpha /$ Infliximab complex detection.

Figure 4: The graph represents the recognition of multispecies sera by the SA-TRIM21-HRP protein. Animal sera (50 ng) were coated onto polystyrene plates, blocked with $1 \%$ BSA, incubated with SA-TRIM21 (0.5 $\mu \mathrm{g} /$ well), and biotinylated HRP (1:2500). Control experiments were performed using immobilized BSA into wells. After washing with PBST $(10 \mathrm{mM} \mathrm{NaCl}), 50 \mu \mathrm{L}$ chromogenic substrate TMB was added to the wells, incubated for 10 minutes, followed by the addition of $50 \mu \mathrm{L} \mathrm{H}_{2} \mathrm{SO}_{4}$ to quench the reaction followed by $\mathrm{OD}_{450} \mathrm{~nm}$ reading using an ELISA plate reader. The data shows the ratio of serum/control OD 450 reading. Experiments were performed in triplicates, and error bars represent standard deviation.

Figure 5: The figure depicts the alignment of IgG heavy chain Fc regions from different mammalian species. The residues in gray are conserved among all sequences. The residues marked in bold represent the Mouse IgG Fc hot spots (H433, N434, and H435) necessary for binding to TRIM21 identified in previous studies (James, Keeble, Khan, Rhodes, \& Trowsdale, 2007). Cat IgG residues H433, S434 and H435 are also shown in bold.

Figure 6: Impact of imidazole elution on IgG binding. Direct ELISA assays using $50 \mathrm{ng}$ immobilized human serum or $50 \mathrm{ng}$ BSA, followed by SA-TRIM21-HRP $(0.5 \mu \mathrm{g})$ or HRP-coupled Protein A/G incubation and washing with imidazole-containing buffers. Chromogenic substrate TMB was added to the wells, incubated for 10 minutes, followed by the addition of $50 \mu \mathrm{L} \mathrm{H}_{2} \mathrm{SO}_{4}$ and $\mathrm{OD}_{450}$ reading. The data shows the ratio of serum/control $\mathrm{OD}_{450}$ reading. Experiments were performed in triplicates, and error bars represent standard deviation.

Figure 7: Western blotting detection of CYP1A from protein extracts of mullet fish micro- 
somes. Lane 1, $250 \mathrm{ng}$ of protein extract; Lane 2, $125 \mathrm{ng}$; Lane 3, $62.5 \mathrm{ng}$; Lane $43.12 \mathrm{ng}$; Lane $51.56 \mathrm{ng}$; Lane $60.78 \mathrm{ng}$. Rabbit IgG anti CYP1A was used as the primary antibody at a dilution ratio of 1:7500 in TBS $/ 1 \%$ casein. SA-TRIM21 at $0.25 \mu \mathrm{g} / \mathrm{mL}$ was added to the nitrocellulose membrane in TBS $/ 1 \%$ casein for rabbit IgG recognition. Biotin HRP (1:2500) was added followed by detection using Luminol based reagent (ECL Scienco Biotech) and chemioluminescent detector.

A

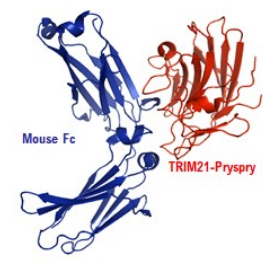

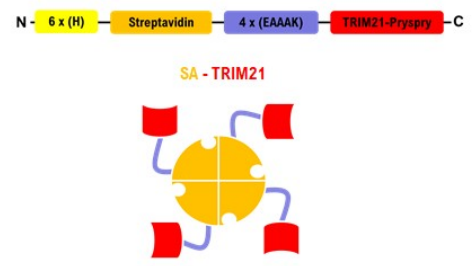

C

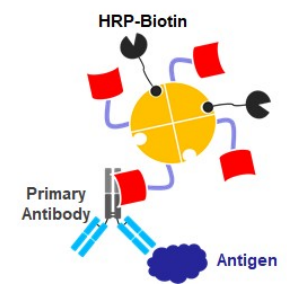

A

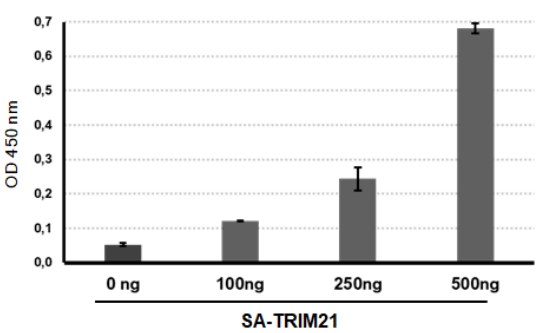

B

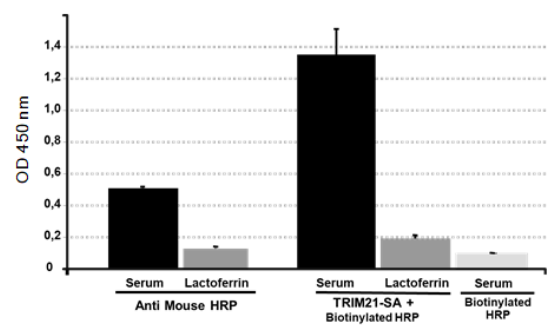



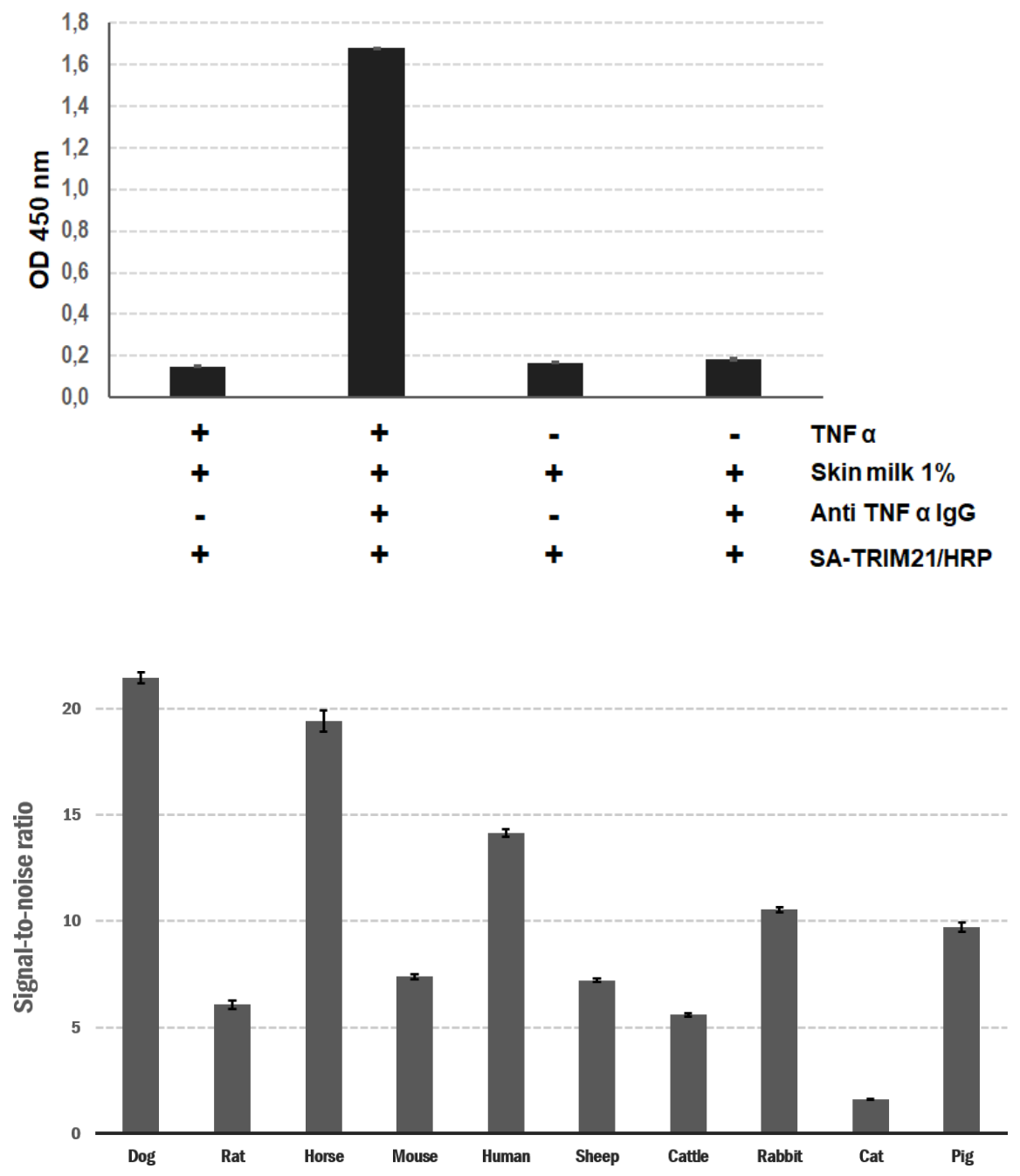

$\begin{array}{llc} & & \begin{array}{c}\text { SA-TRIM 21 } \\ \text { detection }\end{array} \\ \text { Dog } & \text { WQRGDTFICAVMHEALHNHYTQKSLSHSPGK } & \star \star \star \\ \text { Horse } & \text { WQQGTTFTCAVMHEALHNHYTEKSVSKSPGK } & * \star \star \\ \text { Human } & \text { WQQGNVFSCSVMHEALHNHYTQKSLSLSPGK } & \star \star \\ \text { Rabbit } & \text { WQRGDVFTCSVMHEALHNHYTQKSISRSPGK } & \star \star \\ \text { Pig } & \text { WQRGDLFQCAVMHEALHNHYTQKSVSQTPGK } & \star \star \\ \text { Mouse } & \text { WQQGEIFTCSVVHEALHNHHTQKNLSRSPGK } & \star \\ \text { Sheep } & \text { WQEGDTYACVVMHEALHNHYTQKSISKPPGK } & \star \\ \text { Cattle } & \text { WQEGDTYTCVVMHEALHNHYTQKSTSKSAGK } & \star \\ \text { Rat } & \text { WQQGNTFTCSVLHEGLHNHTEKSLSHSPGK } & \star \\ \text { Cat } & \text { WQRGNTYTCSVSHEALHSHHTQKSLTQSPGK } & -\end{array}$



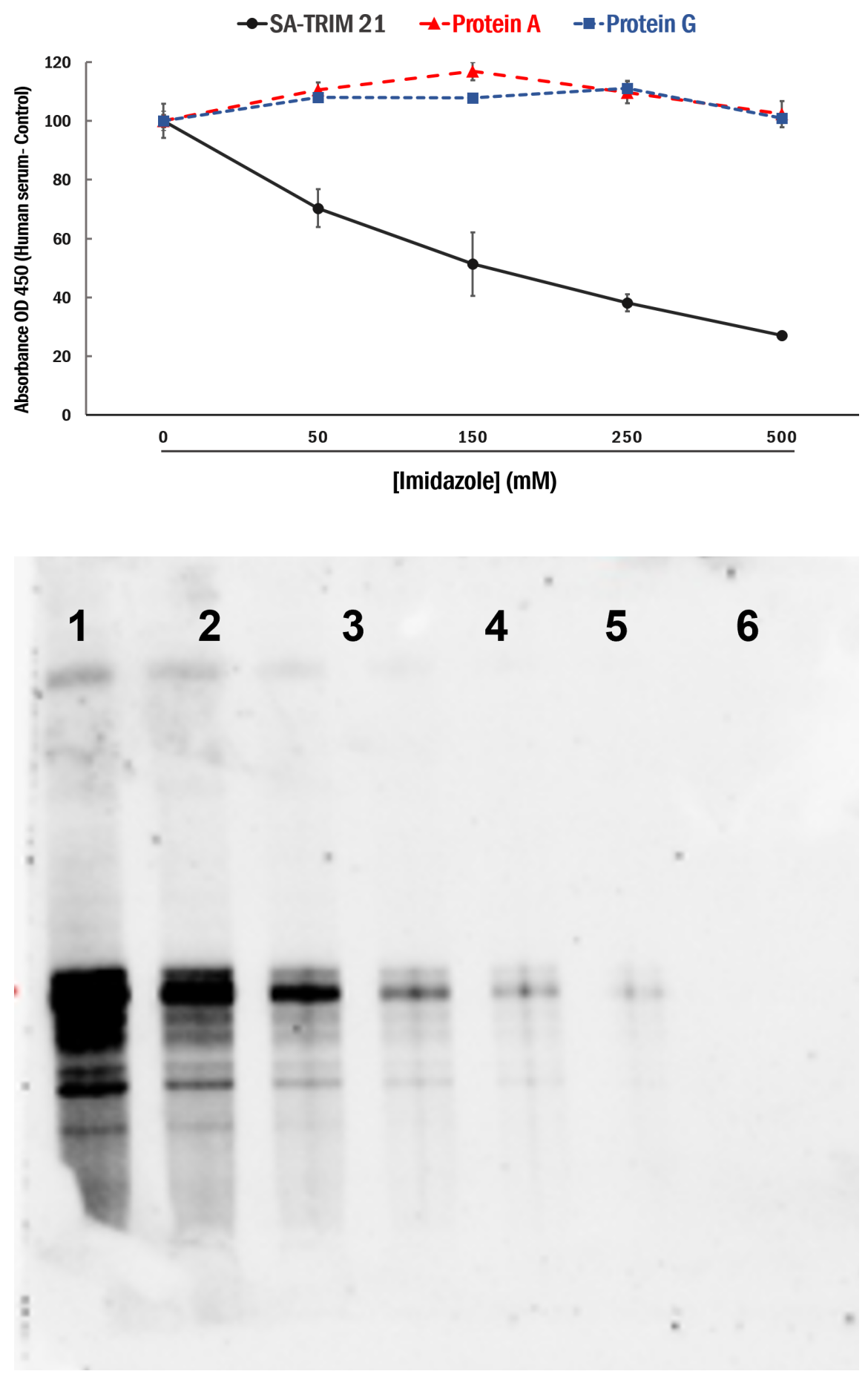